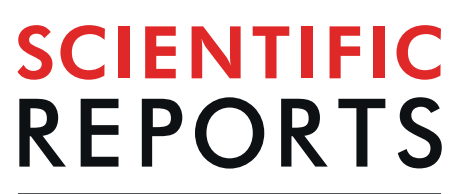

natureresearch

Check for updates

\title{
SOX3 promotes generation of committed spermatogonia in postnatal mouse testes
}

\author{
Dale McAninch ${ }^{1}$, Juho-Antti Mäkelä $\mathbb{C}^{2,3,4,6}$, Hue M. La ${ }^{2,3,6}$, James N. Hughes ${ }^{1}$, \\ Robin Lovell-Badge $\mathbb{I}^{5}$, Robin M. Hobbs $\mathbb{1}^{2,3 凶}$ \& Paul Q. Thomas ${ }^{1 凶}$
}

SOX3 is a transcription factor expressed within the developing and adult nervous system where it mostly functions to help maintain neural precursors. Sox 3 is also expressed in other locations, notably within the spermatogonial stem/progenitor cell population in postnatal testis. Independent studies have shown that Sox3 null mice exhibit a spermatogenic block as young adults, the mechanism of which remains poorly understood. Using a panel of spermatogonial cell marker genes, we demonstrate that Sox 3 is expressed within the committed progenitor fraction of the undifferentiated spermatogonial pool. Additionally, we use a Sox3 null mouse model to define a potential role for this factor in progenitor cell function. We demonstrate that Sox 3 expression is required for transition of undifferentiated cells from a GFR 1 1 self-renewing state to the NGN3 + transit-amplifying compartment. Critically, using chromatin immunoprecipitation, we demonstrate that SOX3 binds to a highly conserved region in the $\mathrm{Ngn} 3$ promoter region in vivo, indicating that $\mathrm{Ngn} 3$ is a direct target of SOX3. Together these studies indicate that SOX3 functions as a pro-commitment factor in spermatogonial stem/progenitor cells.

SOX3 is a member of the SOX (Sry-related HMG box) family of transcription factors (TFs), of which there are 20 members in mammals. SOX TFs are expressed within many tissues of the mouse embryo and regulate a range of important cellular activities including self-renewal, specification and differentiation ${ }^{1,2}$. SOX TFs bind to variants of the SOX consensus motif (A/TA/TCAAA/TG) via a highly conserved HMG domain that shares at least 50\% sequence identity with the founding member SRY. Sox1, Sox2 and Sox3 have high similarity across their entire open reading frame and together comprise the SoxB1 subgroup. SoxB1 genes are expressed in neural progenitor cells throughout the entire vertebrate neuroaxis and are generally down-regulated during differentiation ${ }^{3,4}$. Loss-of-function and overexpression experiments in a range of vertebrate systems indicate important and overlapping roles for SOXB1 factors in the generation and maintenance of neural stem/progenitor cells ${ }^{5-8}$. SOX3 is also expressed in progenitor cells outside of the nervous system, including the postnatal testis. However, the role of SOX3 in stem/progenitor cell maintenance in these tissues is less well understood.

Spermatogenesis is the fundamental biological process required for the generation of sperm from progenitor cells via mitosis, meiosis, and a complex program of cellular differentiation. Importantly, in mammals, as in many other animals, sustained spermatogenesis in the adult is dependent on a resident population of germline cells with self-renewal potential. In the mouse testis, this stem cell activity is contained within a heterogeneous population of germ cells known as undifferentiated spermatogonia that develop from gonocytes (foetal germ cells) during the first week of postnatal development. The undifferentiated pool is located in the basal layer of the seminiferous tubules, and is composed of cells of distinct topologies; isolated type A-single spermatogonia $\left(\mathrm{A}_{\mathrm{s}}\right)$ and interconnected chains of 2 or more cells formed from incomplete cytokinesis during cell division referred to as A-paired $\left(\mathrm{A}_{\mathrm{pr}}\right)$ and A-aligned $\left(\mathrm{A}_{\mathrm{al}}\right)$ spermatogonia, respectively9. Upon commitment to differentiate, cells convert to type $A 1$ spermatogonia, which then undergo a series of rapid mitotic divisions prior to meiosis and sperm formation. Besides having distinct cell division kinetics, differentiating spermatogonia can be distinguished from

\footnotetext{
${ }^{1}$ School of Biological Sciences and Robinson Research Institute, University of Adelaide, Adelaide, SA, 5005, Australia. ${ }^{2}$ Australian Regenerative Medicine Institute, Monash University, Melbourne, VIC, 3800, Australia. ${ }^{3}$ Development and Stem Cells Program, Monash Biomedicine Discovery Institute and Department of Anatomy and Developmental Biology, Monash University, Melbourne, VIC, 3800, Australia. ${ }^{4}$ Present address: Institute of Biomedicine, University of Turku, Turku, Finland. ${ }^{5}$ Laboratory of Stem Cell Biology and Developmental Genetics, The Francis Crick Institute, London, NW1 1AT, UK. ${ }^{6}$ These authors contributed equally: Juho-Antti Mäkelä and Hue M. La. ${ }^{\bowtie}$-mail: robin. hobbs@monash.edu; paul.thomas@adelaide.edu.au
} 
undifferentiated cells by expression of the receptor tyrosine kinase c-KIT plus DNA methyltransferases $3 \mathrm{~A}$ and 3B (DNMT3A/DNMT3B) $)^{10,11}$.

All cells within the undifferentiated pool may possess self-renewal potential ${ }^{12}$. However, only a small subset of this population act as stem cells in the steady-state tissue, with a majority of undifferentiated cells being primed to differentiate and therefore acting as committed progenitor/transit-amplifying cells ${ }^{13}$. The fate tendencies of undifferentiated cells correlate with gene expression patterns and chain length. Specifically, steady-state stem cells express Gfral, encoding a co-receptor for the key niche-derived growth factor glial cell line derived neurotrophic factor (GDNF) and exist primarily as $A_{s}, A_{p r}$ and some short-chained $A_{a l}$ cells ${ }^{14}$. A primitive subset of GFR $\alpha 1+A_{s}$ and $A_{p r}$ spermatogonia with potent stem cell activity and marked by expression of transcription factors EOMES and PDX1 has also recently been described ${ }^{15,16}$. In contrast, the majority of $\mathrm{A}_{\mathrm{al}}$ spermatogonia express $\mathrm{Ngn} 3$ and Rarg and are usually differentiation-committed ${ }^{17-20}$. Interestingly, lineage-tracing studies have demonstrated that a small fraction of the NGN3 + population is still capable of forming stable long-lived clones within the testis ${ }^{19}$. Moreover, NGN3 $+\mathrm{A}_{\mathrm{al}}$ cells occasionally fragment to shorter chains plus $\mathrm{A}_{\mathrm{s}}$ cells and may revert gene expression patterns to a GFR $\alpha 1+$ state, demonstrating the dynamic nature of the stem cell pool ${ }^{16,21}$. This limited contribution of NGN3 + cells to the steady-state self-renewing pool is also enhanced under conditions of tissue regeneration ${ }^{19}$. However, in contrast to GFR $\alpha 1+$ spermatogonia, NGN3/RAR $\gamma+$ undifferentiated cells are sensitive to retinoic acid, a key endogenous differentiation stimulus, which promotes a differentiation-committed fate ${ }^{18}$.

As transition from the GFR $\alpha 1+$ to NGN3 + state switches the predominant fate of undifferentiated cells from self-renewal to differentiation, it must be tightly regulated to ensure tissue homeostasis. A limited number of factors have been directly implicated in regulation of this transition. For instance, the SOHLH1/2 transcription factors and mTORC1-signalling pathway promote exit from a GFR $\alpha 1+$ state while the NANOS2 RNA binding protein prevents the GFR $\alpha 1+$ to NGN3 + transition via direct inhibition of both Sohlh2 mRNA translation and mTORC1 activation ${ }^{20,22-25}$. Despite the importance of such factors and pathways in fate transitions within the undifferentiated pool, the relevant downstream effectors remain poorly characterised.

Sox 3 is one of a number of identified target genes of SOHLH1/2 within the testis and is reported to play a role in spermatogenesis, whereby Sox 3 deletion causes a block in spermatogenesis that is most severe in mice bred on the $\mathrm{C} 57 \mathrm{Bl} / 6$ genetic background ${ }^{23,26,27}$. However, the exact nature of this spermatogenic block and the underlying molecular mechanisms are not fully understood. Through use of a Sox3-GFP knock-in mouse model we now confirm that Sox 3 is specifically expressed within the committed/differentiation-destined progenitor fraction of the undifferentiated pool and we define its critical role in the GFR $\alpha 1+$ to NGN3 + spermatogonial transition.

\section{Results}

SOX3 expression is restricted to committed spermatogonial progenitor cells. Previous studies have shown that Sox3 expression in the testis is restricted to spermatogonial populations within the basal layer of the seminiferous tubules ${ }^{8,26,27}$. Through use of a SOX3-specific antibody ${ }^{4}$, we confirmed by immunofluorescence (IF) analysis that SOX3 protein is restricted to spermatogonia of wild type (WT) adult testis (Fig. 1A). Spermatogenesis occurs in a coordinated, cyclic process that can be divided into 12 stages in the mouse. Sections of tubules at a given stage contain defined populations of spermatogonia, spermatocytes and developing spermatids at distinct differentiation and maturation steps ${ }^{9,28}$. Importantly, SOX3-positive spermatogonia were present at all stages of the seminiferous epithelium cycle, indicating that Sox3 is expressed in the undifferentiated population (Fig. 1B). Moreover, spermatogonia expressing Sox3 displayed low levels of Cyclin D1 (Ccnd1), a marker predominantly expressed by differentiating spermatogonia (Fig. 1A $)^{29,30}$. In contrast to the stage-independent presence of SOX3-positive cells, spermatogonia expressing CCND1 were predominantly found in stage I-VI tubules in which populations of differentiating spermatogonia are the most abundant (Fig. 1B).

In order to better define the identity of the SOX3-positive population we next performed IF analysis of prepubertal, WT postnatal day 7 (P7) testis, which is relatively enriched in undifferentiated spermatogonia. Comparison of SOX3 expression with that of promyelocytic leukaemia zinc finger (PLZF), which is expressed throughout the undifferentiated pool ${ }^{31,32}$, revealed extensive overlap (Fig. 1C,D). Analysis of adult and juvenile testis therefore suggested that SOX3 is broadly expressed in the undifferentiated population. To investigate this further, we compared SOX3 expression with that of GFR $\alpha 1$, a marker for the self-renewing fraction of undifferentiated spermatogonia ${ }^{14}$. In comparison to the pronounced co-expression of SOX3 with PLZF, we found a limited overlap in expression of SOX3 and GFR $\alpha 1$ (Fig. 1E), suggesting that within the undifferentiated population, SOX3 is preferentially expressed in the committed progenitor fraction ${ }^{23}$.

To further characterise the expression of SOX3 in spermatogonia, we also performed IF analysis on cultures of undifferentiated spermatogonia derived from juvenile WT mice ${ }^{31}$. SOX3 expression was compared to that of PLZF and the transcription factor SALL4, which is expressed in undifferentiated and differentiating spermatogo$\mathrm{nia}^{33}$. Consistent with previous studies, PLZF and SALL4 were expressed by essentially all cells within the colonies of cultured cells (Fig. 1F) ${ }^{33}$. In contrast, SOX3 expression was clearly heterogeneous. Given that these cultures are considered to contain a mix of both stem and committed progenitor cells ${ }^{34}$, our data support the conclusion that SOX3 expression is restricted to a subset of undifferentiated cells, likely representing the committed progenitor fraction, consistent with previous reports ${ }^{8,26,27}$.

Notably, from IF analysis of P7 testis sections, we confirmed that essentially all SOX3 + cells were positive for spermatogonial marker SALL4 but that (SOX3) expression was restricted to a subset of the SALL4+ population $(32.7 \pm 8.0 \%$ of SALL $4+$ cells were SOX $3+$, mean \pm s.e.m, $n=3$ mice, $>70$ tubule cross-sections scored per sample) (Fig. 2A). In contrast, no overlap in expression was found between SOX3 and EOMES, a marker of the most primitive cells within the GFR $\alpha 1+$ self-renewing fraction (Fig. $2 \mathrm{~B})^{15,16}$. Combined, our results indicate that (SOX3) expression delineates a subset of differentiation committed/primed spermatogonia.

Finally, to confirm the expression pattern of SOX3 within mature stem and progenitor spermatogonial populations, we compared its expression with that of a number of distinct spermatogonial markers by wholemount 

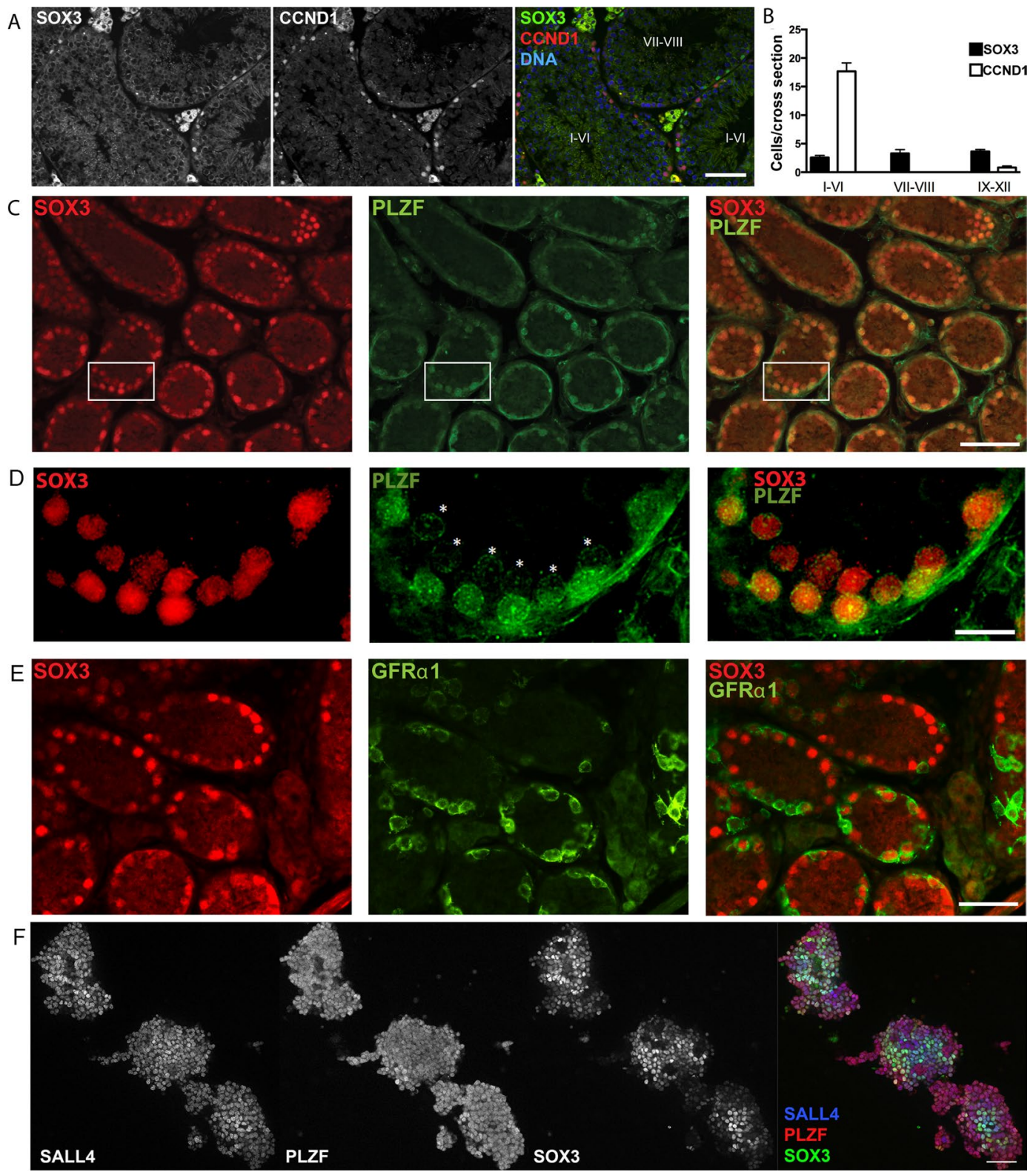

Figure 1. SOX3 expression is found within a subset of undifferentiated spermatogonia. (A) IF of adult testis cross sections showing expression of SOX 3 is restricted to spermatogonia. Note the staining in Leydig cells is non-specific. (B) The number of SOX3 + spermatogonia remains constant, independent of the stage of seminiferous epithelium cycle, whereas CCND1 + spermatogonia are more prevalent in stage I-VI tubules. (C) IF of SOX3 and PLZF in P7 testis cross sections demonstrates an extensive overlap, with only a few SOX3-/ PLZF + spermatogonia present. (D) 60X magnification of white box in (C) highlighting variations in PLZF expression from low (*) to high. (E) IF of SOX3 and GFR $\alpha 1$ in P7 testis cross-sections showing limited overlap of expression. (F) IF of SOX3, PLZF and SALL4 in cultures of undifferentiated spermatogonia derived from juvenile mice, PLZF and SALL4 are detected within essentially all cells, while SOX3 is only present within a subset of cells. Scale bars are $50 \mu \mathrm{m}$. (A,C,E\&F), $10 \mu \mathrm{m}(\mathrm{D})$.

analysis of adult seminiferous tubules (Fig. 3). Importantly, IF for GFR $\alpha 1$ and SOX3 in adult tubules demonstrated that expression of these proteins largely marked distinct spermatogonial populations, in agreement with our previous results (Fig. 1E). GFR $\alpha 1$ primarily labelled $A_{s}$ and $A_{p r}$ cells while SOX3 was present in GFR $\alpha 1$-negative SALL4-positive $\mathrm{A}_{\mathrm{al}}$ (Fig. 3A). Antibodies to GFR $\alpha 1$ and SOX3 used in wholemount analysis are both raised in goat and are visualized in the same fluorescence channel but can be distinguished by cell membrane vs. nuclear staining pattern (Fig. 3A and S1). Rather, we found that SOX3 was co-expressed in chains of undifferentiated spermatogonia plus cells at early differentiation stages with genes that mark committed progenitor fractions, including RAR $\gamma$ and LIN28A (Fig. 3B,C and data not shown) ${ }^{18,32}$. In contrast, chains of c-KIT + spermatogonia at mid-to-late stages of differentiation $\left(\mathrm{A}_{3}\right.$ to $\mathrm{B}$ ) expressed low or undetectable levels of SOX3 (Fig. 3D) ${ }^{10,11,16,30}$. 


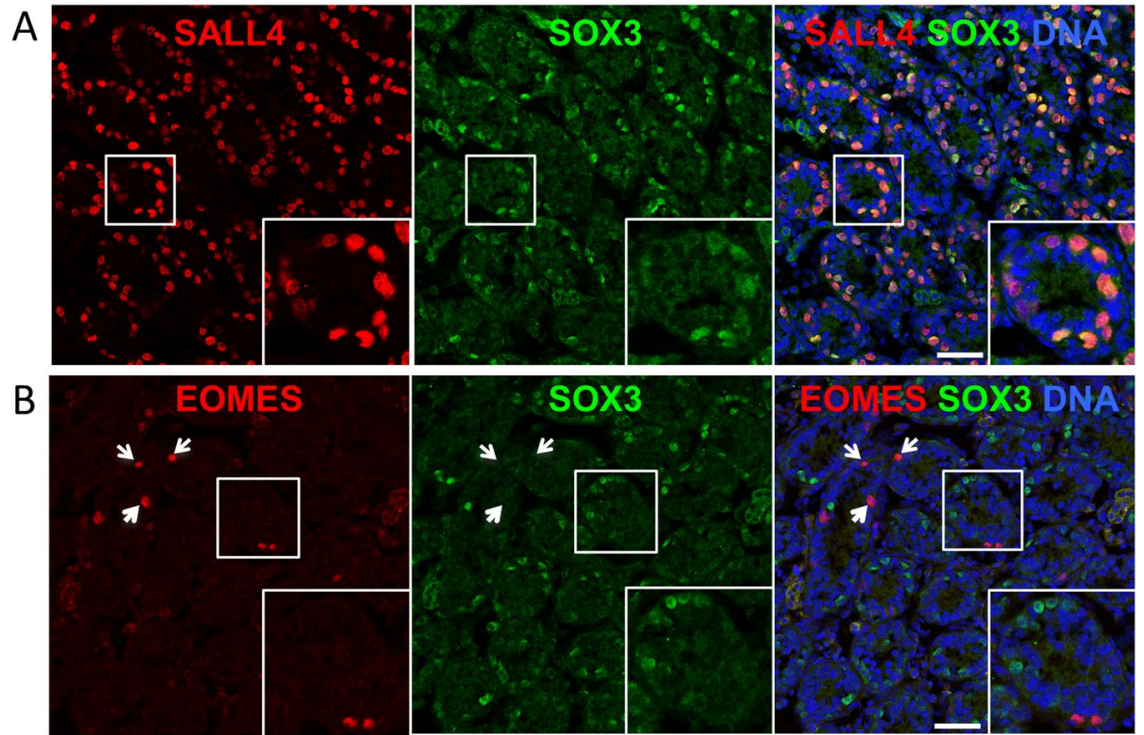

Figure 2. Characterising the expression of SOX3 in juvenile testis. (A,B) Representative IF analysis of SOX3 and markers of spermatogonia (SALL4) and primitive self-renewing cells (EOMES) in testis sections from P7 mice ( $n=3$ mice). Insets show higher magnification details of indicated regions. Arrowheads indicate EOMES + SOX3- spermatogonia. Scale bars are $50 \mu \mathrm{m}$.

Taken together, our data demonstrate that SOX3 expression is selectively upregulated upon transition from the self-renewing to the differentiation-primed/committed progenitor state within the undifferentiated population of both juvenile and adult testes. It is subsequently downregulated as they differentiate further.

Early postnatal defect in 129/Svj Sox3 null testes. Spermatogenesis phenotypes have been reported in Sox3 null mice on mixed and C57BL/6 inbred backgrounds $s^{8,26,35}$. To investigate whether spermatogenesis is also affected on a 129/Svj inbred background, Sox3 null mice were backcrossed and examined for testis abnormalities. No significant difference in testis weight or morphology (Fig. S2A,B) was detected in Sox3 null mice at postnatal day 7 (P7; Fig. S2A,B; WT $=5.3 \pm 0.2 \mathrm{mg} ; \mathrm{KO}=5.1 \pm 0.4 \mathrm{mg}$ ). Histological analysis also failed to reveal any gross defects at this stage (Fig. S3). In contrast, Sox3 null testes were significantly smaller than WT testis at P14, P21 (Fig. S2C-F) and at 6 months of age. Histological analysis revealed an abundance of germ cell-depleted tubules in Sox3 null testes consistent with previous reports ${ }^{8,26,35}$ (Fig. S3E,F). To address whether elevated programmed cell death might account for testis hypoplasia in Sox 3 null mice, we performed TUNEL staining on testis sections. No difference in the number of apoptotic cells was observed between WT or Sox3 null testis at P7 (Fig. S3C,D).

To further investigate the cellular mechanism that underpins the spermatogenic block in Sox 3 null testes, we compared expression of spermatogonial cell markers in WT and Sox3 null testis at P7. We reasoned that although Sox3 null testes were not hypoplastic at this stage, the primary molecular/cellular $\operatorname{defect}(\mathrm{s})$ underpinning the defect would likely be present, given that Sox3 is expressed at this time point (Fig. 1). Expression of Oct4/Pou5f1, $P l z f, I d 4$ and Ecad were not significantly different, suggesting that the number of Type A spermatogonia is not grossly affected by the absence of Sox3 (Fig. 4A) ${ }^{31,36}$. Further, expression of these markers was not significantly altered in KO testis at P14, P21 and P28. In contrast, Ngn3, a marker of differentiation-primed undifferentiated spermatogonia, was substantially reduced at P7 (Fig. 4A) and remained significantly lower throughout postnatal testis development (P14, P21 and P28) (Fig. 4B-D), as observed previously in B6 KO mice ${ }^{27}$. Conversely, expression of Gfral, a marker for the self-renewing fraction of undifferentiated spermatogonia, was significantly higher in Sox3 null testis compared to WT (Fig. 4). Gfra1 expression remained significantly elevated at P14 and P21 although it had apparently normalised by postnatal week 4 (Fig. 4B-D). Interestingly, expression of $I d 4$, a marker associated with transplantable stem cell activity that is detected in a subset of the GFR $\alpha 1$-positive population in adults, but is more broadly expressed by spermatogonia during postnatal development, was not significantly altered by loss of Sox3 (Fig. 4A-D) ${ }^{37}$. While the significance of unaltered Id4 expression is unclear, the increase in Gfra 1 and reduction in Ngn 3 expression in response to Sox 3 deletion suggests a relative increase in self-renewing spermatogonial subsets and a corresponding decrease in differentiation-primed progenitors.

To confirm these observations in the mature spermatogonial pool, we isolated undifferentiated cells $($ EpCAM $+\alpha 6$-integrin $+c$-KIT-) from wildtype control and Sox3 KO adults and analysed gene expression by RT-qPCR (Fig. 5) ${ }^{38}$. Within the EpCAM+ germ cell fraction of Sox3 KO testis a significantly greater proportion of cells were in the $\alpha 6$-integrin $+c$-KIT- undifferentiated cell gate compared to controls (Fig. 5B,C), suggesting that spermatogonial differentiation was disrupted in the Sox3 KO and undifferentiated cells accumulated with age. In agreement with analysis of total testis extracts during postnatal development, Sox $3 \mathrm{KO}$ adult undifferentiated spermatogonia exhibited significantly lower expression of $\mathrm{Ngn} 3$ while other stem and progenitor-associated markers were mostly comparable to controls. Expression of Gfral was increased in Sox3 KO undifferentiated cells, although not significantly $(P=0.0569)$, consistent with previous results (Figs. 4 and 5D). Combined, our results 


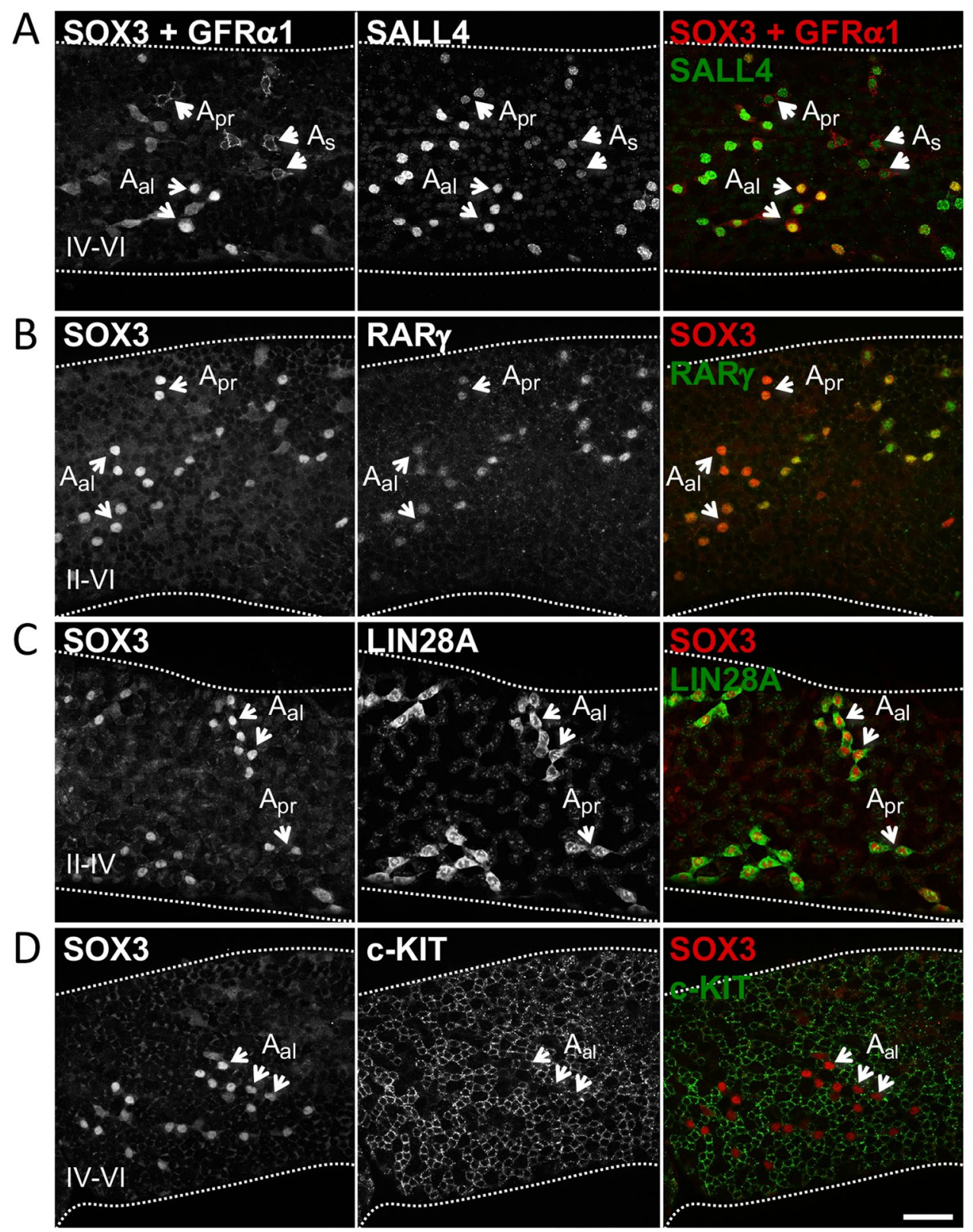

Figure 3. Characterising the expression of SOX 3 in adult testis. Assessing co-expression of SOX3 with a panel of undifferentiated and differentiated spermatogonia cell markers in adult seminiferous tubules by wholemount IF. SOX 3 shows limited overlap in expression with stem cell-associated marker GFR $\alpha 1$ (A) but is co-expressed with progenitor markers RAR $\gamma(\mathbf{B})$ and LIN28A (C) within the undifferentiated pool. SOX3 is expressed at low levels or is undetectable in mid-late stage differentiating spermatogonia marked with c-KIT (D). Note that antibodies to SOX3 and GFR $\alpha 1$ are both raised in goat and detected in the same fluorescence channel. Cell staining patterns are used to distinguish GFR $\alpha 1$ (cell membrane) and SOX3 (nucleus). Selected undifferentiated cells and stages of tubules are indicated. Representative images are shown $(\mathrm{n}=4$ mice). Scale bars are $50 \mu \mathrm{m}$.

support the involvement of SOX3 in stem-to-progenitor transition in the male germline and specifically link SOX3 with expression of $\mathrm{Ngn} 3$, a marker of differentiation-primed undifferentiated spermatogonia ${ }^{21}$.

SOX3 promotes exit from the GFR 1 1-positive spermatogonial state. To further investigate the cellular mechanism that underpins elevated expression of Gfra1 in Sox3 null testis, we first performed IF analysis of P7 testis sections. Importantly, we observed a significant increase in the total number of GFR 1 positive cells per tubule cross-section in Sox 3 null testis compared to WT testis (mean of $12.3 \pm 0.28$ versus $6.2 \pm 0.19$ cells/ tubule, $P<0.0001$; Fig. 6A). This relative expansion of the GFR $\alpha 1$-positive population may suggest that Sox3 deficiency resulted in a differentiation block at the stem-to-progenitor cell transition or increased self-renewing divisions of-GFR $\alpha 1$-expressing cells. Alternatively, given the dynamics of cell transitions within the undifferentiated 
A.

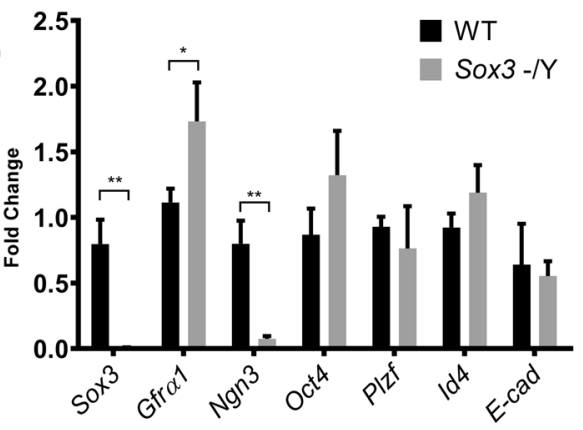

B.

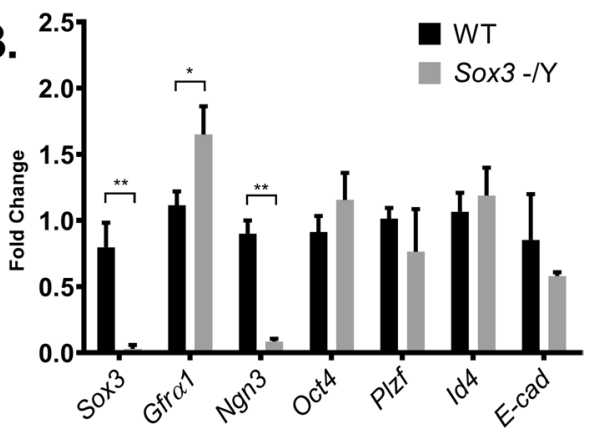

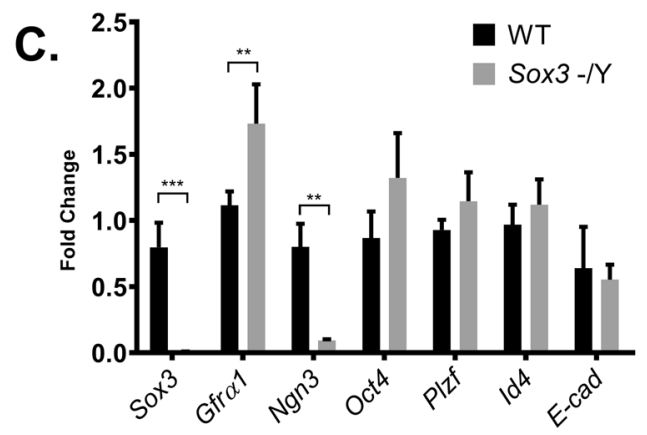

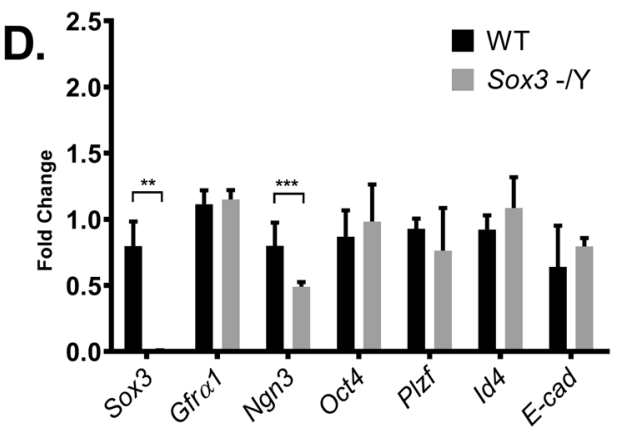

Figure 4. Comparative analysis of $\operatorname{Sox}^{-/ Y}$ and WT testis gene expression. Expression analysis of spermatogonia cell markers Sox3, Gfra1, Ngn3, Oct4, Plzf, Id4 and E-Cad in P7 (A), P14 (B), P21(C) and P28 (D) testes. n =4 for each genotype, $\mathrm{P}<0.05(*), \mathrm{P}<0.01(* *), \mathrm{P}<0.001(* * *)$ as determined by t-test. Data represented as mean \pm s.d.

compartment ${ }^{21}$, it might represent an inability to maintain a stable progenitor population and increased reversion of committed cells to a self-renewing state.

To investigate these distinct possibilities, we took advantage of a unique feature of our Sox3-deficient model. Namely, that Sox3 deletion is accompanied by insertion of a GFP reporter gene into the Sox3 locus ${ }^{8}$. Analysis of GFP expression in Sox3 null testis therefore allows identification of committed progenitor populations that are usually marked by Sox3 expression in the WT setting. From WT and Sox 3 null testis we therefore scored the number of uncommitted stem cells (GFR $\alpha 1+/$ SOX3- and GFR $\alpha 1+/ G F P$ - respectively), transitional/early committed progenitor cells (GFR $\alpha 1+$ /SOX $3+$ and GFR $\alpha 1+/$ GFP +$)$ and committed progenitor cells (GFR $\alpha 1-/$ SOX3 + and GFR $\alpha 1-/ G F P+)$ (Fig. 6B). Importantly, no significant difference was detected in the total number of cells expressing these distinct marker combinations. However, significant differences were detected in the relative abundance of two subpopulations. Firstly, the number of cells that exhibited a committed progenitor phenotype (GFR $\alpha 1-/ G F P+v s$. GFR $\alpha 1-/ S O X 3+)$ was significantly reduced in Sox3 null testes as compared to WT controls. Secondly, there was a significant increase in the number of uncommitted (GFR $1+/ G F P-v s$. GFR $\alpha 1+/$ SOX3-) stem cells in the Sox 3 null testes. While populations of transitional cells (GFR $\alpha 1+/ G F P+v s$. GFR $\alpha 1+/$ SOX $3+$ ) were not significantly altered upon loss of Sox3 at this early postnatal age, transitional stem-progenitor cells were found to accumulate in Sox3 null adults (see below). Our results indicate that while the total population of stem and progenitor spermatogonia is relatively unaffected in the juvenile Sox 3 null testis, there is a shift in balance from stem to committed progenitor cell phenotype. This suggests that Sox 3 promotes the stable transition from stem to progenitor cell states and is consistent with changes in Gfral and Ngn3 expression in Sox3 null testis (Figs. 4 and 5).

To further investigate this phenotype and the consequences of inefficient stem to progenitor cell conversion on the spermatogenic pathway, we analysed Sox3-deficient adult testis by whole mount IF of seminiferous tubules (Fig. 7A). In this analysis, SALL4 was used as a marker of both undifferentiated and differentiating spermatogonia, while expression of DNMT3B identified differentiating spermatogonia ${ }^{11,33}$. The distinct stages of the seminiferous tubule areas were then defined according to the differentiation stage of resident spermatogonial populations as described ${ }^{28,39}$. Consistent with analysis of juvenile testis sections, the basal layer of adult Sox3 null tubules demonstrated pronounced increases in the density of GFR $\alpha 1$-positive cells throughout the seminiferous epithelium cycle (Fig. 7A). Notably, while in WT tubules GFR $\alpha 1$-positive cells were most frequently present as $A_{s}$ and $A_{p r}$, in Sox 3 null testis they were often found as $A_{a l}$ chains of 4 or more cells. The increased GFR 1 -positive chain length in Sox 3 null testis was accompanied by evidence of disruption to the spermatogonial differentiation pathway. Specifically, at stages II-V, when WT tubules contained abundant populations of GFR $\alpha 1-/ S A L L 4+$ / DNMT3B- $\mathrm{A}_{\mathrm{al}}$ cells; Sox3-deficient $\mathrm{A}_{\mathrm{al}}$ often abnormally retained GFR $\alpha 1$ expression (Fig. 7A). Moreover, between 
A

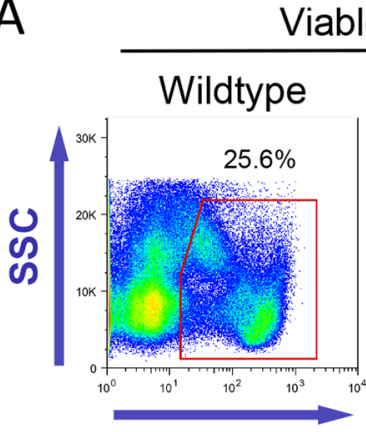

EpCAM
B

EpCAM+ cells

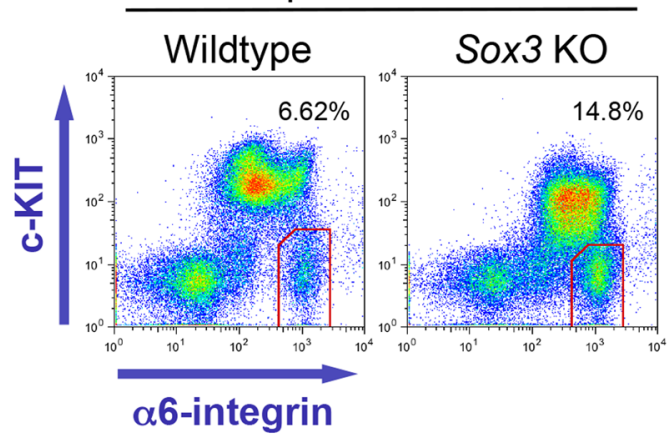

C
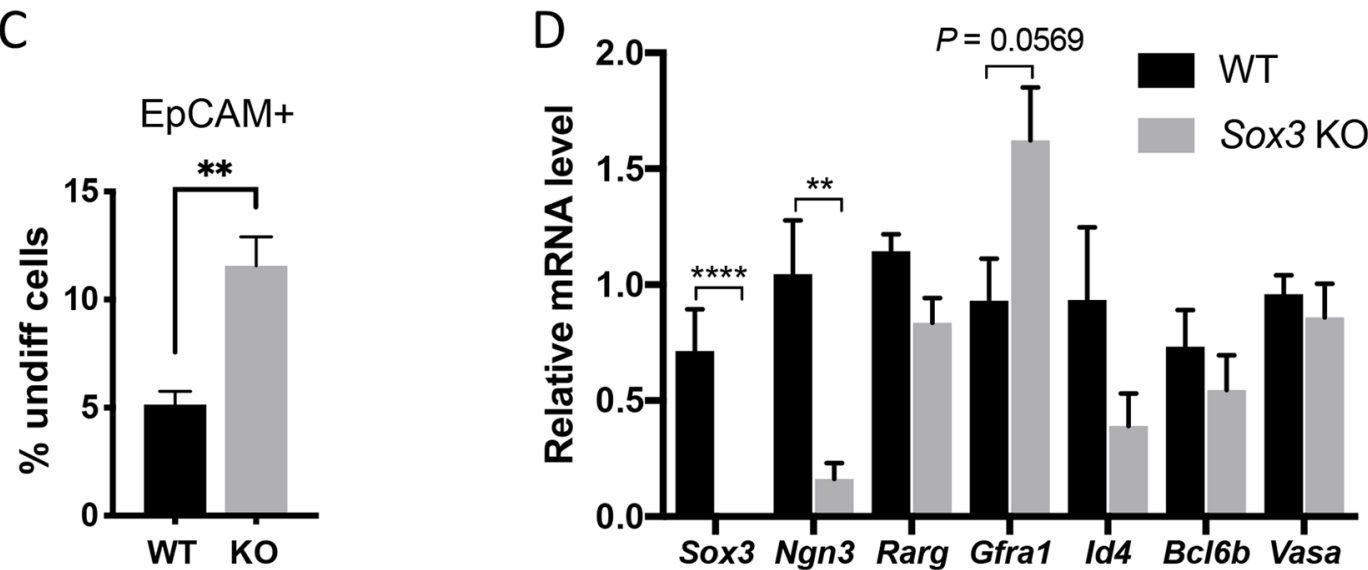

Figure 5. Isolation and analysis of Sox3 null adult undifferentiated spermatogonia. (A,B) Flow-sorting strategy for isolation of undifferentiated spermatogonia (EpCAM $+c-K I T-\alpha 6$-integrin + ) for gene expression analysis. Percentages of cells within gates are indicated. (C) Graph shows percentage of EpCAM+ germ cells within c-KIT- $\alpha 6$-integrin + undifferentiated cell gate from flow cytometry analysis of wildtype and Sox 3 null adult testis of $A$ and B. Mean values \pm s.e.m. are shown $(n=5$ wildtype and $n=6$ Sox 3 null mice). Significance was determined by two-tailed unpaired $t$-test, $\mathrm{P}<0.01(* *)$. (D) RT-qPCR analysis of sorted undifferentiated spermatogonia (EpCAM + c-KIT- $\alpha 6$-integrin + ) from wildtype and Sox3 null adult testis. Expression levels are corrected to $\beta$-actin and normalized to a control sample. Mean values \pm s.e.m. shown $(n=5$ wildtype and $n=6$ Sox3 null mice). Significance was determined by two-tailed unpaired $t$-test and selected $\mathrm{P}$ values are indicated, $\mathrm{P}<0.01(* *), \mathrm{P}<0.0001(* * * *)$.

stages V-XI, during which essentially all WT $A_{a l}$ cells initiate differentiation and generate GFR $\alpha 1-/ S A L L 4+/$ DNMT3B + differentiating A-type spermatogonia, a substantial fraction of $\mathrm{A}_{\mathrm{al}}$ cells in the Sox3-deficient testis persisted in a GFR $\alpha 1+/$ SALL4+/DNMT3B- undifferentiated state (Fig. 7A). Consequently, the density of differentiating spermatogonia at times appeared lower in Sox3 null tubules as compared to WTs.

This data indicates that Sox3-deficient $\mathrm{A}_{\mathrm{al}}$ cells, while morphologically resembling differentiation-primed undifferentiated spermatogonia do not appropriately down-regulate GFR $\alpha 1$, a key functional marker of the stem cell state ${ }^{40}$. Moreover, these GFR $\alpha 1+\mathrm{A}_{\mathrm{al}}$ cells subsequently enter the differentiation pathway less efficiently than their WT GFR $\alpha 1-\mathrm{A}_{\mathrm{al}}$ counterparts. Consistent with our observations, the majority of GFR $\alpha 1+\mathrm{A}_{\mathrm{al}}$ that accumulated in Sox3 null adults did not express RAR $\gamma$ (Fig. 7B), a marker of differentiation-primed progenitors required for differentiation commitment ${ }^{17,18}$. Interestingly, however, a minor subset of GFR $\alpha 1+\mathrm{A}_{\mathrm{al}}$ cells in the knockout did express $\operatorname{RAR} \gamma$, indicating an accumulation of transitional undifferentiated cells exhibiting both stem and progenitor characteristics. Such a stem-progenitor transitional state is rarely detected in WT adult testis, as is presumably short-lived but persists in the absence of Sox3, as undifferentiated cells appear unable to adopt a stable committed progenitor state (Fig. 7B). Note that RAR $\gamma+$ GFR $\alpha 1-$ progenitors were still found in Sox3 null testis indicating that stem to progenitor conversion was not completely abrogated, in agreement with our analysis of juvenile testis (Figs. 6B and 7B).

Ngn3 is a direct target of SOX3. Given the near complete failure to activate Ngn3 expression in Sox3 null postnatal testes, we investigated the possibility that Ngn3 can be a relevant target of SOX3 in germline cells. Previous ChIP-Seq studies of neural progenitors ${ }^{41,42}$ identified a SOX3 binding peak and single SOX consensus motif (SOCM) approximately $500 \mathrm{bp}$ upstream of the transcriptional start site of Ngn3 (Fig. 8A). This genomic region is highly conserved in mammals suggesting it may function as an enhancer. To investigate SOX3 binding to this region, we performed SOX3 ChIP-PCR on P7 mouse testis. Significant enrichment of SOX3 binding to this 
A

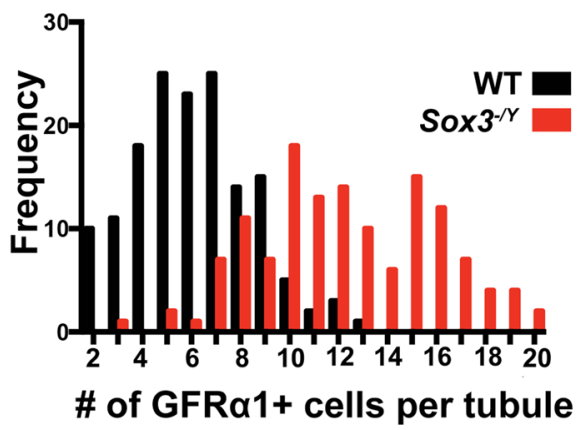

B

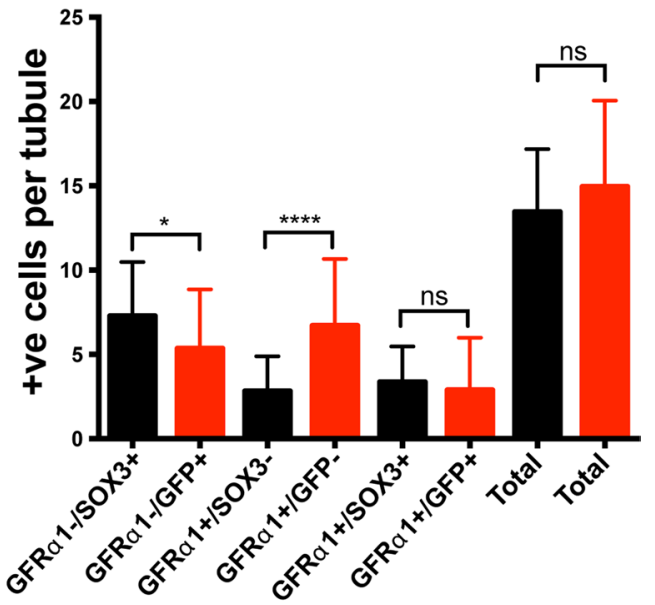

C
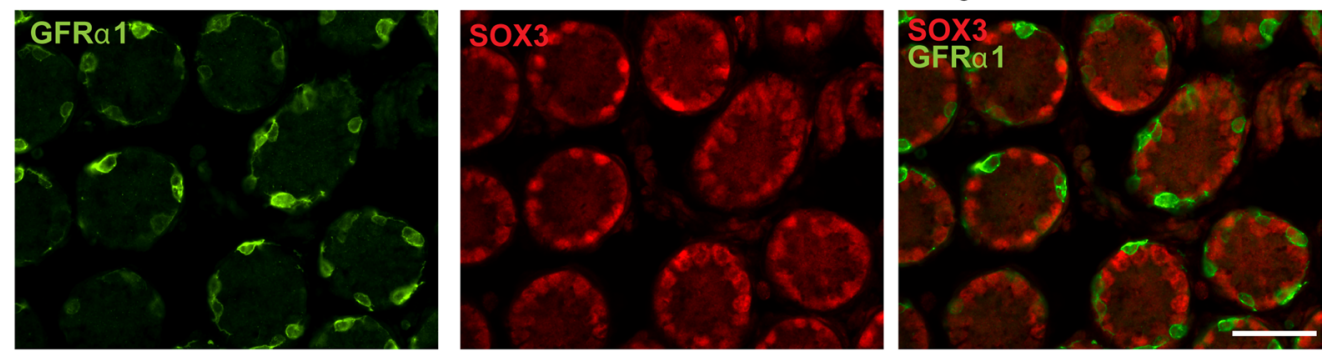

D
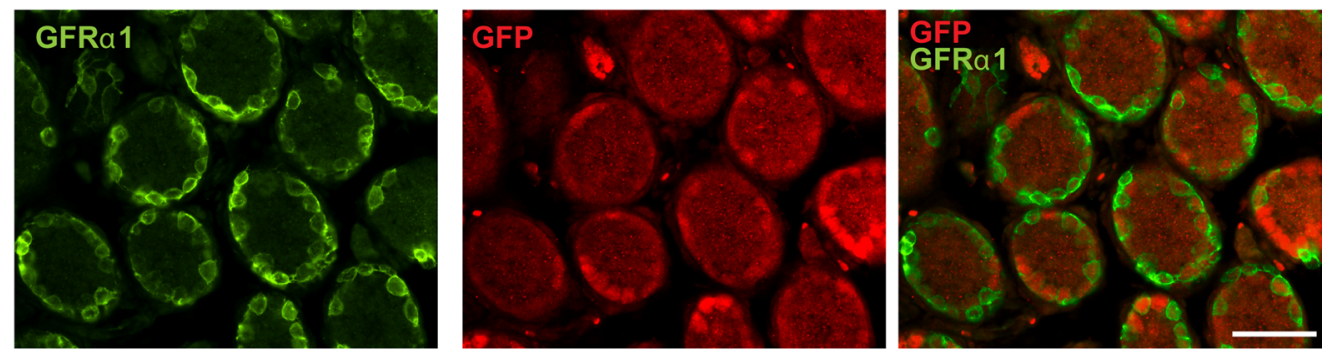

Figure 6. Increased number of GFR $\alpha 1+$ spermatogonia in So $x 3^{-/ Y}$ testis. (A) Frequency plot showing more GFR $\alpha 1+$ cells per tubule in Sox3 null testis cross-sections $(12.3+/-0.28)$ compared to WT $(6.2+/-0.19)$, $\mathrm{P}<0.0001$. (B) Cell counts of the different spermatogonia cell identities as marked by SOX3/GFP and or GFR $\alpha 1$ staining. IF of WT testis cross sections at P7 (C), and Sox3 null testis sections (D), staining for SOX3 (red) and GFR $\alpha 1$ (green). Minimum 10 fields of view per counted section, 3 sections per testis, $\mathrm{n}=3$ for each genotype, not significant (ns), $\mathrm{P}<0.05(*), \mathrm{P}<0.0001(* * * *)$ as determined by Mann-Whitney test. Data represented as mean \pm s.d., scale bar is $50 \mu \mathrm{m}(\mathbf{C}, \mathbf{D})$.

region was detected, suggesting that $\mathrm{Ngn} 3$ is directly activated by SOX3 in vivo (Fig. 8B). As a positive control, we confirmed that SOX 3 in testis cells also binds the SOX3 target gene Dbx1 previously identified in a neural system $^{43}$.

\section{Discussion}

Previous studies have shown that SOX3 is expressed in Type A spermatogonia ${ }^{8,26,27}$; however, these range from stem cells through to committed progenitors and overtly differentiating cells and it was unclear how the expression and function of SOX3 related to this progression. Here we show extensive overlap between SOX3 and multiple markers of undifferentiated spermatogonia (PLZF, LIN28A and SALL4) indicating that Sox3 is expressed within this compartment. Comparison of SOX3 with spermatogonial stem cell markers GFR $\alpha 1$ and EOMES revealed limited or no overlap respectively, indicating that the SOX3-negative spermatogonial population are bona fide stem cells. Taken together, we conclude that Sox3 is not expressed by the steady-state stem cell population (GFR $\alpha 1$-positive) but is rapidly upregulated during initial differentiation commitment steps of these cells. The lack of Sox3 expression in DNMT3A/B, c-KIT and CCND1-positive $\mathrm{A}_{3}$ to B spermatogonia indicates that Sox3 is subsequently downregulated at later stages of differentiation. Thus, Sox 3 expression closely mirrors that of $\mathrm{Ngn3}$, a key marker of committed progenitor spermatogonia ${ }^{44}$. Definitive identification of $\mathrm{Ngn3}$ - expressing cells in vivo is hampered by the lack of a specific antibody and therefore requires knock-in GFP reporter mice. Therefore, given the availability of commercial specific antibodies, SOX3 provides a useful alternative marker for committed type A spermatogonia. 
A
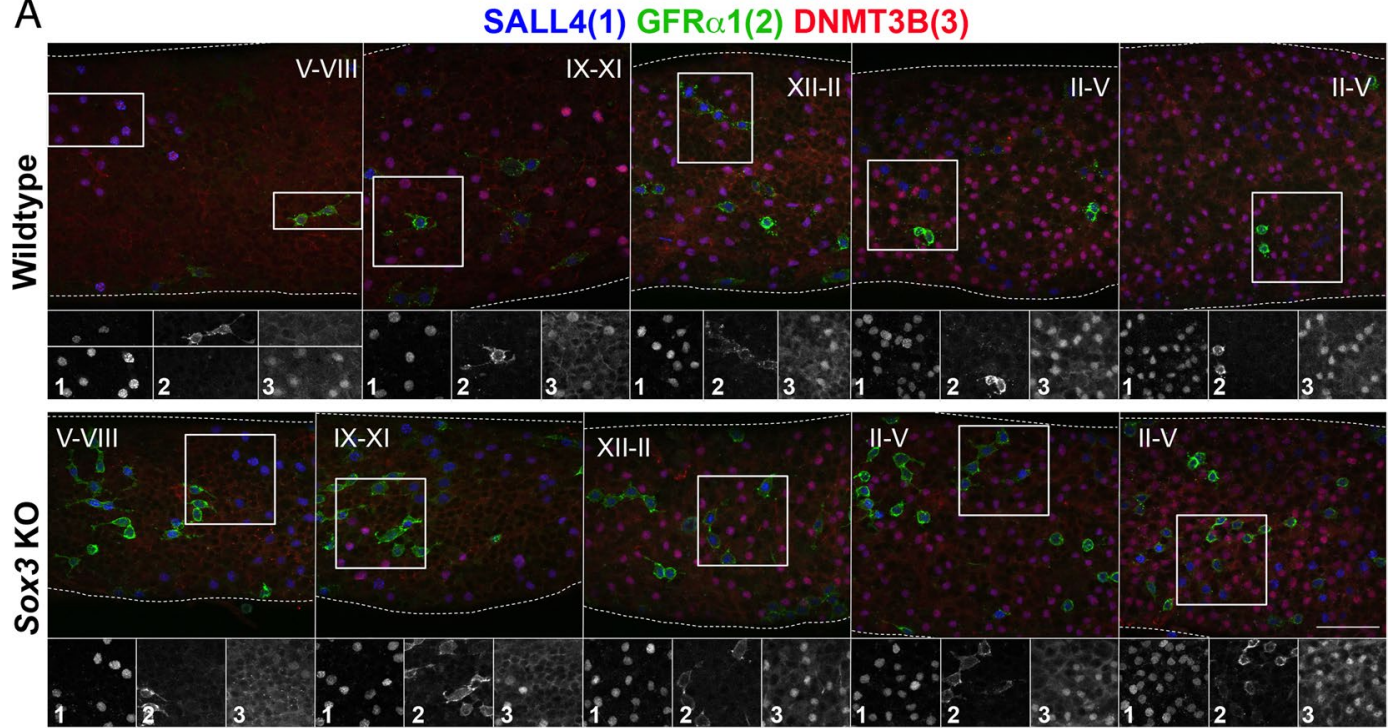

B

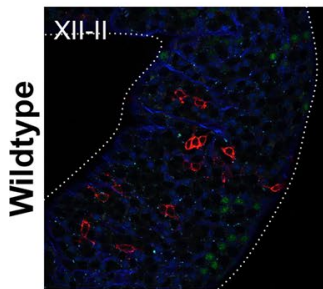

GFR $\alpha 1(1) \operatorname{RAR} \gamma(2)$ DNMT3A(3)
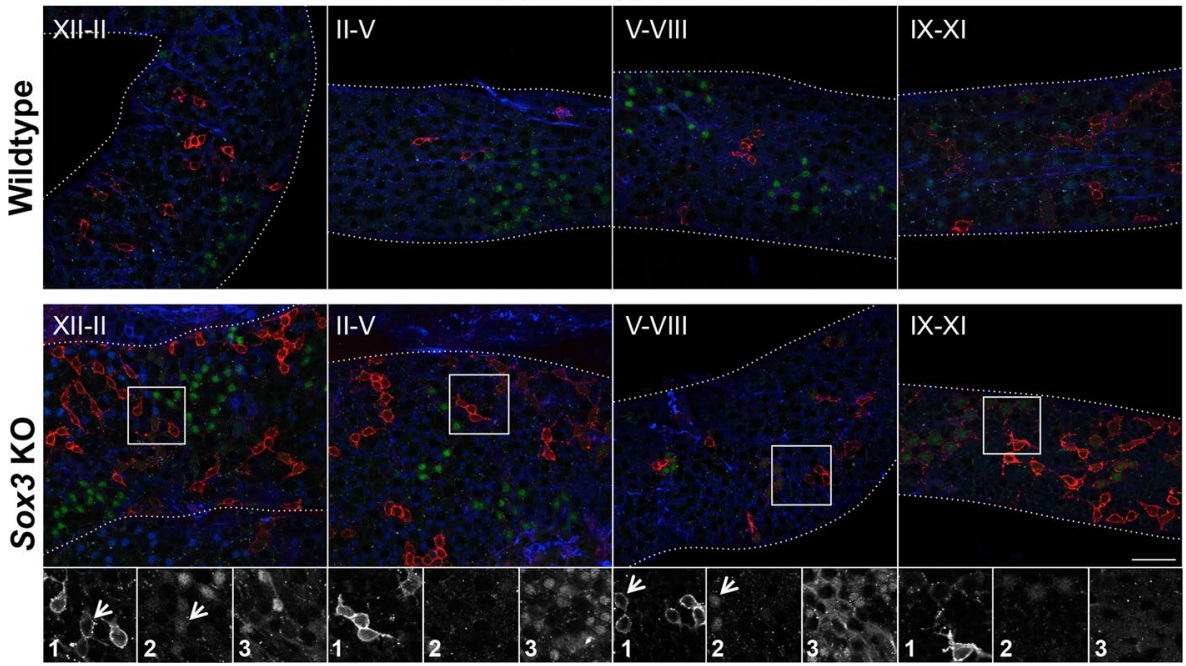

Figure 7. Analysis of Sox3 null adult seminiferous tubules by whole mount IF. Wholemount IF analysis of WT and Sox3 knockout adult seminiferous tubules for SALL4, DNMT3B, GFR $\alpha 1$ (A) and GFR $\alpha 1$, RAR $\gamma$, DNMT3A $(\mathbf{B})$ at the indicated spermatogenic stages. Grayscale panels show individual immunostaining within the indicated area. Arrowheads in $(\mathbf{B})$ indicate GFR $\alpha 1+/ \operatorname{RAR} \gamma+$ transitional cells found relatively frequently in Sox3 knockout tubules but rarely in WT samples. Scale bars are 50 $\mu \mathrm{m}$.

Within the undifferentiated spermatogonial pool, GFR $\alpha 1+$ cells have a high self-renewal potential while NGN3 + cells are primed to differentiate ${ }^{14,21}$. The distinct fates of these undifferentiated cell subsets are defined by relative sensitivity to retinoic acid (RA), a key endogenous regulator of spermatogonial differentiation. Specifically, NGN3 + cells are responsive to RA due to expression of the RA receptor RAR $\gamma$, while GFR $\alpha 1$ + cells lack RAR $\gamma$ expression and are consequently unresponsive to RA ${ }^{18,20}$. Combined, our data demonstrate that SOX 3 is critically required for formation of GFR $\alpha 1$-/NGN3 + differentiation-primed progenitors from the GFR $\alpha 1$ + /NGN3- stem cell pool. Moreover, we find that Sox3 is specifically upregulated during this stem-to-progenitor transition and SOX3 directly targets Ngn3 (see below). This suggests that SOX3 plays a central and cell-autonomous role in promoting exit from a GFR $\alpha 1+$ stem cell state. Sox3 deletion therefore results in an accumulation of GFR $\alpha 1+$ cells and a substantially reduced capacity to generate RA-sensitive, differentiation-primed GFR $\alpha 1$ - progenitors within the undifferentiated pool. Consequently, this leads to a reduction in production of differentiating spermatogonia and ineffective or blocked spermatogenesis (Fig. 9). In adults, loss of Sox3 was also accompanied by an accumulation of transitional undifferentiated cells expressing both stem and progenitor markers, reflecting inefficient stem to progenitor conversion.

It is also possible that in the absence of SOX3, differentiation-primed GFR $\alpha 1$-negative progenitors are still successfully generated within the undifferentiated pool but are not stably maintained and rapidly revert to a 

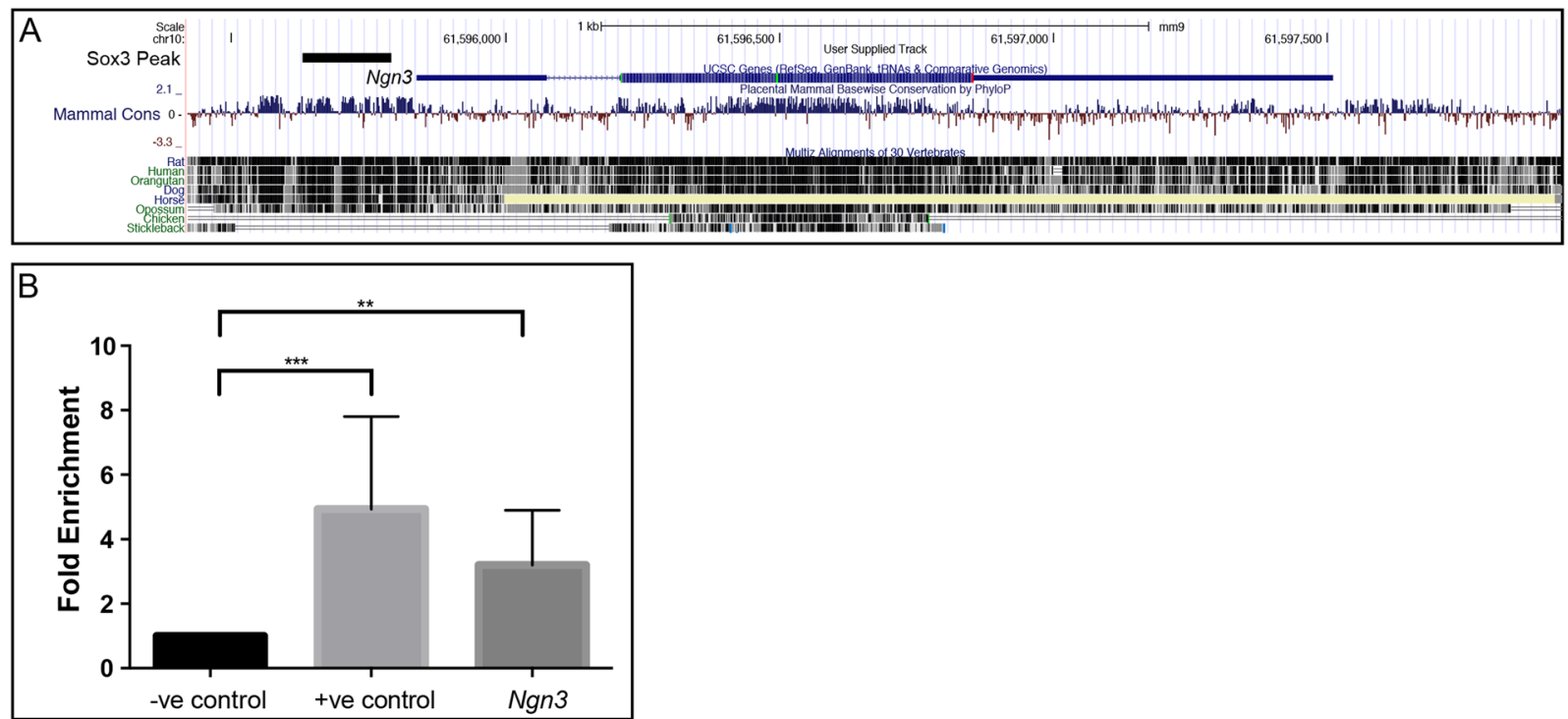

Figure 8. $\mathrm{Ngn} 3$ is a direct SOX 3 target gene in spermatogonia. UCSC Genome Browser view of published SOX3 ChIP-seq data ${ }^{42}$ from neural progenitor cells showing a SOX3 binding site within the upstream promoter region of Ngn3 (A). ChIP-PCR for SOX3 in P7 testis (B), demonstrating SOX3 binding upstream of the Ngn3 promoter (Ngn3), $\mathrm{P}<0.05(*), \mathrm{P}<0.01(* *)$ as determined by t-test, data represented as mean \pm s.d. $-\mathrm{ve}$ control represents a site within Notch 1 known not to bind SOX $3,+$ ve control represents a site within intron 2 of $D b x 1$ previously validated as a binding site of $\mathrm{SOX}^{41}$.

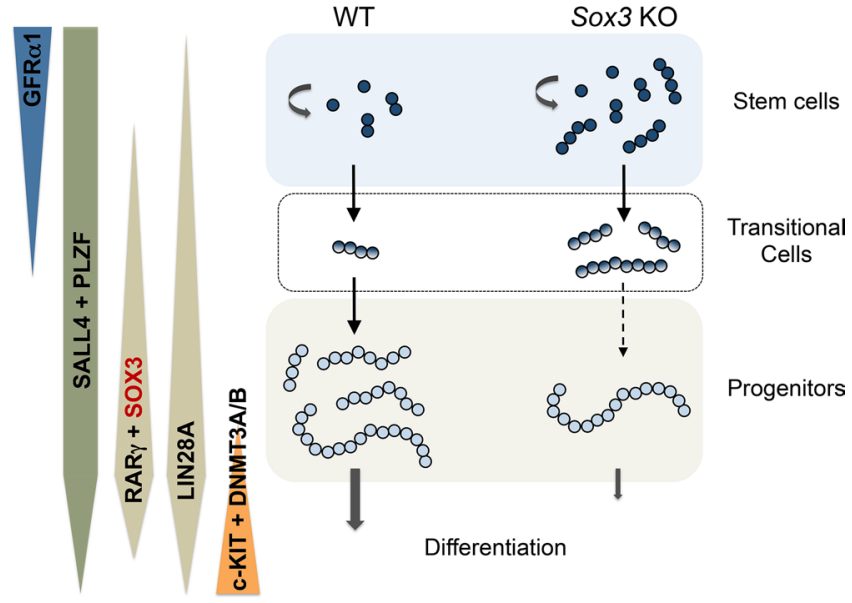

Figure 9. Model of spermatogenesis in WT and Sox $3 \mathrm{KO}$ adult testis. GFR $\alpha 1$ is found within the spermatogonial stem cell pool of WT testis, before being switched off as the cells progress into a progenitor cell state. Conversely, SOX3 is not found within the stem cell population and expression is switched on upon conversion into progenitor cells. SOX3 + progenitor cells differentiate and continue through the spermatogenesis pathway. Additional markers delineating the distinct differentiation stages of spermatogonia are indicated. In Sox3 knockout (KO) testis, the loss of SOX3 leads to an accumulation of GFR $1+$ cells, and a reduction in the capacity to form differentiation-primed GFR $\alpha 1$ - progenitor cells. This ultimately leads to a reduction in the production of differentiating spermatogonia. In adult WT testis, GFR $\alpha 1+$ stem cells are mostly present as $A_{s}$ and $A_{p r}$ while GFR $\alpha 1+A_{a l}$ cells are frequently found in Sox 3 null testis. Stem-progenitor transitional $A_{a l}$ cells expressing both GFR $\alpha 1$ and RAR $\gamma$ also accumulate in Sox 3 knockouts but are rarely found in WT tubules. We propose that SOX3 plays an essential role in efficient stem to progenitor conversion within the undifferentiated spermatogonial population.

GFR $\alpha 1+$ state, mimicking the cellular dynamics observed during testis regeneration ${ }^{21}$. This possibility could be tested by fate-mapping progenitor populations upon Sox3 deletion, through use of Ngn3-CreER plus reporter lines or by developing an equivalent Sox3-CreER transgenic model ${ }^{19}$. Based on current models ${ }^{13,21}$, progenitor-to-stem cell reversion upon Sox 3 deletion would be predicted to be accompanied by fragmentation of longer undifferentiated progenitor chains back to $A_{s}$ and $A_{p r}$ GFR $\alpha 1+$ cells. However, in the Sox 3 null adult, we find GFR $\alpha 1+$ cell chain lengths to be increased compared to WT controls, arguing against this reversion model. Rather, our 
results suggest that the physiological process of differentiation priming that normally occurs as chain length increases within the undifferentiated pool does not occur in the Sox3 null testis (Fig. 9). Consequently, a large proportion of the Sox3-deficient $\mathrm{A}_{\text {al }}$ population abnormally retains gene expression patterns and properties of the stem cell state, including being refractory to differentiation stimuli such as RA. This GFR $\alpha 1+A_{a l}$ population generally lacks expression of RAR $\gamma$, a marker of progenitor cells required for RA-dependent spermatogonial differentiation ${ }^{17,18}$.

We have provided evidence that Ngn3 is a direct target gene of SOX3 in spermatogonia. NGN3 is a prototypical marker of the differentiation-destined progenitor state and knockdown of $\mathrm{Ngn} 3$ expression in cultured undifferentiated spermatogonia disrupts differentiation upon transplantation in vivo ${ }^{21,45}$. Therefore, the loss of $\mathrm{Ngn3}$ expression upon Sox 3 deletion may be responsible for reduced efficiency of the stem cell population to progress to a committed progenitor state. Collectively our data define the window in which SOX3 acts during spermatogenesis, as well as one critical direct target gene, Ngn3. Further studies of both the regulation and the role of SOX3 will help reveal how type A spermatogonia progress from stem cells to committed precursors and the degree to which these processes are shared between spermatogonial and neuronal progenitors.

\section{Materials and Methods}

Animals. Generation of the Sox3 null mice on a mixed genetic background (129 sv/eV, MF1, CBA and $\mathrm{C} 57 \mathrm{Bl} / 6$ ) has been described previously ${ }^{8}$. Mixed background Sox3 null mice were crossed onto the 129/SvJ genetic background and mice from the F6 generation or from a 129/SvJ, CBA mixed background were used in these studies.

Testis histology and immunofluorescence (IF). Testes were isolated and fixed in $4 \%$ formaldehyde overnight, followed by equilibration of tissues in $30 \%$ sucrose. Testis were set in OCT compound (Tissue-Tek) and cryosectioned on a Leica CM1900 at $16 \mu \mathrm{m}$ thickness. For IF, sections were permeablised with $1 \%$ Triton in PBS for 10 minutes, blocked with $10 \%$ horse serum for 1 hour, followed by overnight incubation with primary antibodies overnight at $4{ }^{\circ} \mathrm{C}$. Sections were washed with PBS and incubated in secondary antibody solution for 1-2 hours, washed in PBS, mounted in ProLong Gold Anitfade Mountant with DAPI (Life Technologies, P-36931) before being cover slipped. Images were captured on a Nikon Ti-E inverted microscope with NIS software (NIKON) using a 20x objective lens. For histology, sections were dehydrated in an increasing methanol series from $10 \%$ to $100 \%$. Sections were stained with haematoxylin and eosin. Whole mount IF of seminiferous tubules was performed as described ${ }^{16,20}$.

Antibodies. Antibodies are detailed previously ${ }^{16,20,30,31,33}$ including $\alpha$ SOX3 (R\&D Systems AF2569), $\alpha$ DNMT3A (Novus Biologicals 64B1446), $\alpha$ DNMT3B (Novus Biologicals 52A1018), $\alpha$ c-KIT (Cell Signaling Technologies \#3074), $\alpha$ LIN28A (Cell Signaling Technologies \#8641) and $\alpha$ Cyclin D1 (Novus Biologicals SP4).

TUNEL assay. TUNEL assays were performed as per manufacturer's instructions (Roche, 11684795910). Briefly, tissue was permeabilised in $0.1 \%$ Triton X-100 for 2 minutes on ice, washed twice with PBS, then incubated with TUNEL reaction mixture for 60 mins at $37 \mathrm{C}$ in a humidified chamber. Tissue was washed 3 times with PBS followed by mounting with ProLong Gold Anitfade Mountant with DAPI.

qPCR. RNA from testis of all mouse ages was extracted by mechanically dissociating tissue in Trizol (Life Technologies) for 10 minutes as per manufacturer's instructions. RNA was run on a $1.5 \%$ RNase free agarose gel to assess integrity. cDNA was generated using the High Capacity RNA to cDNA kit (Life Technologies). Expression profiling from total testis extracts was performed on four WT and four Sox3 null testes at each age, using B-Actin and Eif $4 a$ as reference genes. RT-qPCR was performed using Fast Sybr Green Master Mix (Life Technologies), and run on the ABI 7500 StepOnePlus system, all reactions were completed in triplicate. Isolation and gene expression analysis of adult undifferentiated spermatogonia was performed as described ${ }^{38}$.

Primer sequences. qPCR primers used for gene expression analyses were as follows:

Sox3: F 5'-GAACGCATCAGGTGAGAGAAG-3', R 5'-GTCGGAGTGGTGCTCAGG-3'

Gfra1: F 5'-ATCGGGCAGTACACATCTCTG-3', R 5'-TGTGGTTATGTGGCTGGAGG-3'

Plzf: $\mathrm{F}$ 5'-CCTGGACAGTTTGCGACTGA-3', R 5'-GCCATGTCCGTGCCAGTAT-3'

Ngn3: F 5'-CCCCAGAGACACAACAACCT-3', R 5'-AGTCACCCACTTCTGCTTCG-3'

Oct4: $\mathrm{F}$ 5'-CCCAGGCCGACGTGG-3', R 5'-GATGGTGGTCTGGCTGAACAG-3'

Id4: F 5'-CTCACCCTGCTTTGCTGAGA-3', R 5'-TCACCCTGCTTGTTCACGG-3'

E-Cad: F 5'-TTGCAAGTTCCTGCCATCCT-3', R 5'-CATCATCTGGTGGCAGCAG-3'

$\beta$-Actin: F $5^{\prime}$-CTGCCTGACGGCCAGG-3', R 5'-GATTCCATACCCAAGAAGGAAGG-3'

Eif2: F 5'-TGATGGCACTGGCCCCAACAT-3', R 5'-GCGCCCTCCTTAGTAGCCCAC-3'

qPCR primers used for ChIP-PCR analyses were as follows:

Ngn3: F 5'-GAGAGTTGCTGGGACTGAGC-3', R 5'-AGCTGGATTCCGGACAAAG-3'

Dbx1: (+ve control) F 5'-CTTTGGTCTCCACAAGCTTTCT-3', R 5'-GAATGTGGCCTTTAACAA CTCAC- $3^{\prime}$

Notch1: (-ve control) F 5'-TGTTGTGCTCCTGAAGAACG-3', R 5'-GCAACACTTTGGCAGTCTCA-3'

ChIP-PCR. $\quad$ P7 mouse testis were extracted and tissue was mechanically disassociated in $1 \%$ formaldehyde for 8 minutes at room temperature, followed by neutralisation with $125 \mathrm{mM}$ glycine for 5 minutes at $4{ }^{\circ} \mathrm{C}$. Cells were lysed followed by sonication (Bioruptor, Diagenode) for 15 minutes with 30 s cycling pulses on ice. SOX3 bound chromatin was immunoprecipitated by a goat polyclonal antibody raised against human SOX3 (R\&D systems, AF2569). DNA was recovered after reversing crosslinks and purified by PCR clean-up kit (QIAGEN). 
Three independent ChIP samples were generated each from the material of 4 testis. Each sample was analysed by qRT-PCR as described above, using $1 \%$ input as a reference and ChIP samples from Sox 3 null testis as a negative control.

Ethics statement. Animal experiments were subject to approval by the Animal Ethics Committees of the University of Adelaide and Monash University. All studies were conducted within the principles of animal replacement and reduction and experimental refinement. Animals were monitored daily for evidence of illness and, if distressed, were culled immediately by cervical dislocation by an experienced investigator/animal technician. All the experiments were performed in accordance with the approved guidelines and regulations.

Received: 23 January 2017; Accepted: 19 March 2020;

Published online: 21 April 2020

\section{References}

1. Kamachi, Y. \& Kondoh, H. Sox proteins: regulators of cell fate specification and differentiation. Development 140, 4129-4144, https://doi.org/10.1242/dev.091793 (2013).

2. Reiprich, S. \& Wegner, M. From CNS stem cells to neurons and glia: Sox for everyone. Cell Tissue Res 359, 111-124, https://doi. org/10.1007/s00441-014-1909-6 (2015).

3. Bylund, M., Andersson, E., Novitch, B. G. \& Muhr, J. Vertebrate neurogenesis is counteracted by Sox1-3 activity. Nature neuroscience 6, 1162-1168, https://doi.org/10.1038/nn1131 (2003).

4. Rogers, N. et al. Expression of the murine transcription factor SOX3 during embryonic and adult neurogenesis. Gene expression patterns: GEP 13, 240-248, https://doi.org/10.1016/j.gep.2013.04.004 (2013).

5. Favaro, R. et al. Hippocampal development and neural stem cell maintenance require Sox2-dependent regulation of Shh. Nature neuroscience 12, 1248-1256, https://doi.org/10.1038/nn.2397 (2009).

6. Ferri, A. L. et al. Sox 2 deficiency causes neurodegeneration and impaired neurogenesis in the adult mouse brain. Development 131, 3805-3819, https://doi.org/10.1242/dev.01204 (2004).

7. Nishiguchi, S., Wood, H., Kondoh, H., Lovell-Badge, R. \& Episkopou, V. Sox1 directly regulates the gamma-crystallin genes and is essential for lens development in mice. Genes \& development 12, 776-781, https://doi.org/10.1101/gad.12.6.776 (1998).

8. Rizzoti, K. et al. SOX3 is required during the formation of the hypothalamo-pituitary axis. Nature genetics 36, 247-255, https://doi. org/10.1038/ng1309 (2004).

9. de Rooij, D. G. \& Grootegoed, J. A. Spermatogonial stem cells. Current opinion in cell biology 10, 694-701, https://doi.org/10.1016/ s0955-0674(98)80109-9 (1998).

10. Schrans-Stassen, B. H., van de Kant, H. J., de Rooij, D. G. \& van Pelt, A. M. Differential expression of c-kit in mouse undifferentiated and differentiating type A spermatogonia. Endocrinology 140, 5894-5900, https://doi.org/10.1210/endo.140.12.7172 (1999).

11. Shirakawa, T. et al. An epigenetic switch is crucial for spermatogonia to exit the undifferentiated state toward a Kit-positive identity. Development 140, 3565-3576, https://doi.org/10.1242/dev.094045 (2013).

12. Simons, B. D. \& Clevers, H. Strategies for homeostatic stem cell self-renewal in adult tissues. Cell 145, 851-862, https://doi. org/10.1016/j.cell.2011.05.033 (2011).

13. La, H. M. \& Hobbs, R. M. Mechanisms regulating mammalian spermatogenesis and fertility recovery following germ cell depletion. Cell Mol Life Sci 76, 4071-4102, https://doi.org/10.1007/s00018-019-03201-6 (2019).

14. Hara, K. et al. Mouse spermatogenic stem cells continually interconvert between equipotent singly isolated and syncytial states. Cell stem cell 14, 658-672, https://doi.org/10.1016/j.stem.2014.01.019 (2014).

15. Sharma, M. et al. Identification of EOMES-expressing spermatogonial stem cells and their regulation by PLZF. Elife 8, https://doi. org/10.7554/eLife.43352 (2019).

16. La, H. M. et al. Identification of dynamic undifferentiated cell states within the male germline. Nat Commun 9, 2819, https://doi. org/10.1038/s41467-018-04827-z (2018).

17. Gely-Pernot, A. et al. Spermatogonia differentiation requires retinoic acid receptor gamma. Endocrinology 153, 438-449, https://doi. org/10.1210/en.2011-1102 (2012).

18. Ikami, K. et al. Hierarchical differentiation competence in response to retinoic acid ensures stem cell maintenance during mouse spermatogenesis. Development 142, 1582-1592, https://doi.org/10.1242/dev.118695 (2015).

19. Nakagawa, T., Nabeshima, Y. \& Yoshida, S. Functional identification of the actual and potential stem cell compartments in mouse spermatogenesis. Dev Cell 12, 195-206, https://doi.org/10.1016/j.devcel.2007.01.002 (2007).

20. Hobbs, R. M. et al. Distinct germline progenitor subsets defined through Tsc2-mTORC1 signaling. EMBO Rep 16, 467-480, https:// doi.org/10.15252/embr.201439379 (2015).

21. Nakagawa, T., Sharma, M., Nabeshima, Y., Braun, R. E. \& Yoshida, S. Functional hierarchy and reversibility within the murine spermatogenic stem cell compartment. Science 328, 62-67, https://doi.org/10.1126/science.1182868 (2010).

22. Sada, A., Suzuki, A., Suzuki, H. \& Saga, Y. The RNA-binding protein NANOS2 is required to maintain murine spermatogonial stem cells. Science 325, 1394-1398, https://doi.org/10.1126/science.1172645 (2009).

23. Suzuki, H. et al. SOHLH1 and SOHLH2 coordinate spermatogonial differentiation. Developmental biology 361, 301-312, https://doi. org/10.1016/j.ydbio.2011.10.027 (2012).

24. Zhou, Z. et al. RNA Binding Protein Nanos2 Organizes Post-transcriptional Buffering System to Retain Primitive State of Mouse Spermatogonial Stem Cells. Dev Cell 34, 96-107, https://doi.org/10.1016/j.devcel.2015.05.014 (2015).

25. Busada, J. T. et al. Retinoic acid regulates Kit translation during spermatogonial differentiation in the mouse. Developmental biology 397, 140-149, https://doi.org/10.1016/j.ydbio.2014.10.020 (2015).

26. Laronda, M. M. \& Jameson, J. L. Sox3 functions in a cell-autonomous manner to regulate spermatogonial differentiation in mice. Endocrinology 152, 1606-1615, https://doi.org/10.1210/en.2010-1249 (2011).

27. Raverot, G., Weiss, J., Park, S. Y., Hurley, L. \& Jameson, J. L. Sox3 expression in undifferentiated spermatogonia is required for the progression of spermatogenesis. Developmental biology 283, 215-225, https://doi.org/10.1016/j.ydbio.2005.04.013 (2005).

28. Phillips, B. T., Gassei, K. \& Orwig, K. E. Spermatogonial stem cell regulation and spermatogenesis. Philosophical transactions of the Royal Society of London. Series B, Biological sciences 365, 1663-1678, https://doi.org/10.1098/rstb.2010.0026 (2010).

29. Beumer, T. L., Roepers-Gajadien, H. L., Gademan, I. S., Kal, H. B. \& de Rooij, D. G. Involvement of the D-type cyclins in germ cell proliferation and differentiation in the mouse. Biol Reprod 63, 1893-1898, https://doi.org/10.1095/biolreprod63.6.1893 (2000).

30. Costoya, J. A. et al. Essential role of Plzf in maintenance of spermatogonial stem cells. Nature genetics 36, 653-659, https://doi. org/10.1038/ng1367 (2004).

31. Hobbs, R. M., Seandel, M., Falciatori, I., Rafii, S. \& Pandolfi, P. P. Plzf regulates germline progenitor self-renewal by opposing mTORC1. Cell 142, 468-479, https://doi.org/10.1016/j.cell.2010.06.041 (2010).

32. Buaas, F. W. et al. Plzf is required in adult male germ cells for stem cell self-renewal. Nature genetics 36, 647-652, https://doi. org/10.1038/ng1366 (2004). 
33. Hobbs, R. M. et al. Functional antagonism between Sall4 and Plzf defines germline progenitors. Cell stem cell 10, 284-298, https:// doi.org/10.1016/j.stem.2012.02.004 (2012).

34. Nagano, M. C. \& Yeh, J. R. The identity and fate decision control of spermatogonial stem cells: where is the point of no return? Current topics in developmental biology 102, 61-95, https://doi.org/10.1016/B978-0-12-416024-8.00003-9 (2013).

35. Weiss, J. et al. Sox3 is required for gonadal function, but not sex determination, in males and females. Mol Cell Biol 23, 8084-8091, https://doi.org/10.1128/mcb.23.22.8084-8091.2003 (2003).

36. Tokuda, M., Kadokawa, Y., Kurahashi, H. \& Marunouchi, T. CDH1 is a specific marker for undifferentiated spermatogonia in mouse testes. Biol Reprod 76, 130-141, https://doi.org/10.1095/biolreprod.106.053181 (2007).

37. Chan, F. et al. Functional and molecular features of the Id $4+$ germline stem cell population in mouse testes. Genes \& development 28, 1351-1362, https://doi.org/10.1101/gad.240465.114 (2014).

38. Chan, A. L. et al. Germline Stem Cell Activity Is Sustained by SALL4-Dependent Silencing of Distinct Tumor Suppressor Genes. Stem Cell Reports 9, 956-971, https://doi.org/10.1016/j.stemcr.2017.08.001 (2017).

39. de Rooij, D. G. Stem cells in the testis. International journal of experimental pathology 79, 67-80, https://doi.org/10.1046/j.13652613.1998.00057.x (1998).

40. Sada, A., Hasegawa, K., Pin, P. H. \& Saga, Y. NANOS2 acts downstream of glial cell line-derived neurotrophic factor signaling to suppress differentiation of spermatogonial stem cells. Stem Cells 30, 280-291, https://doi.org/10.1002/stem.790 (2012).

41. Bergsland, M. et al. Sequentially acting Sox transcription factors in neural lineage development. Genes \& development 25, 2453-2464, https://doi.org/10.1101/gad.176008.111 (2011).

42. McAninch, D. \& Thomas, P. Identification of highly conserved putative developmental enhancers bound by SOX3 in neural progenitors using ChIP-Seq. PLoS One 9, e113361, https://doi.org/10.1371/journal.pone.0113361 (2014).

43. Rogers, N., McAninch, D. \& Thomas, P. Dbx1 Is a Direct Target of SOX3 in the Spinal Cord. PLoS One 9, e95356, https://doi. org/10.1371/journal.pone.0095356 (2014).

44. Yoshida, S. et al. The first round of mouse spermatogenesis is a distinctive program that lacks the self-renewing spermatogonia stage. Development 133, 1495-1505, https://doi.org/10.1242/dev.02316 (2006).

45. Kaucher, A. V., Oatley, M. J. \& Oatley, J. M. NEUROG3 is a critical downstream effector for STAT3-regulated differentiation of mammalian stem and progenitor spermatogonia. Biol Reprod 86(164), 161-111, https://doi.org/10.1095/biolreprod.111.097386 (2012).

\section{Acknowledgements}

We thank Monash Micro Imaging Facility for technical assistance. We are especially grateful for the experimental support provided by Eva Chan and Mia De Seram. An Australian Research Council grant awarded to PT and RH supported this research (\#DP140103965) HML is supported by an Australian Government Research Training Program (RTP) Scholarship and JM was supported by a fellowship from the Sigrid Jusélius Foundation. RLB acknowledges support from the Francis Crick Institute. The Australian Regenerative Medicine Institute is supported by grants from the State Government of Victoria and Australian Government.

\section{Author contributions}

D.M. R.H. and P.T. conceived the study. Experiments were performed by D.M., J.M. and H.L. and analysed by D.M., J.M., H.L., J.H., R.L.B, R.H. and P.T.; D.M., R.H. and P.T. wrote the manuscript; and all authors revised the manuscript.

\section{Competing interests}

The authors declare no competing interests.

\section{Additional information}

Supplementary information is available for this paper at https://doi.org/10.1038/s41598-020-63290-3.

Correspondence and requests for materials should be addressed to R.M.H. or P.Q.T.

Reprints and permissions information is available at www.nature.com/reprints.

Publisher's note Springer Nature remains neutral with regard to jurisdictional claims in published maps and institutional affiliations.

Open Access This article is licensed under a Creative Commons Attribution 4.0 International License, which permits use, sharing, adaptation, distribution and reproduction in any medium or format, as long as you give appropriate credit to the original author(s) and the source, provide a link to the Creative Commons license, and indicate if changes were made. The images or other third party material in this article are included in the article's Creative Commons license, unless indicated otherwise in a credit line to the material. If material is not included in the article's Creative Commons license and your intended use is not permitted by statutory regulation or exceeds the permitted use, you will need to obtain permission directly from the copyright holder. To view a copy of this license, visit http://creativecommons.org/licenses/by/4.0/.

(c) The Author(s) 2020 